\title{
Sensor for Accumulated Charge Detection in Packaged Insulation Layer of Insulated Gate Bipolar Transistor Power Devices
}

\author{
Tatsuo Takada, ${ }^{1 *}$ Kimio Hijikata, ${ }^{1}$ Weiwang Wang, ${ }^{2}$ and Takashi Inoue ${ }^{3}$ \\ ${ }^{1}$ Measurement and Electric Machine Control Laboratory, Tokyo City University, \\ Tamazutsumi, Setagaya, Tokyo 158-8557, Japan \\ ${ }^{2}$ State Key Laboratory of Electrical Insulation and Power Equipment, School of Electrical Engineering, \\ Xi'an Jiaotong University, Xi'an, Shaanxi 710049, China \\ ${ }^{3}$ A \& D Company, Limited, \\ Higashi-Ikebukuro, Toshima, Tokyo 170-0013, Japan
}

(Received August 25, 2018; accepted July 23, 2019)

Keywords: power device, IGBT module, electric charge accumulation, insulation layer, $Q(t)$ method

A compact system for detecting charge accumulation in the insulation layer of power electronic devices such as insulated gate bipolar transistor (IGBT) modules was developed. The amount of electric charge accumulated in IGBT modules at high de voltages (100 to $5000 \mathrm{~V}$ ) and in a wide temperature range $\left(20\right.$ to $\left.180{ }^{\circ} \mathrm{C}\right)$ was measured using the system consisting of two units. The battery-operated sensing and transmission unit $\left(500 \times 700 \times 300 \mathrm{~mm}^{3}\right)$ was connected in series to an IGBT module to which various dc voltages were applied at various temperatures. The collected data were transmitted to a data receiving unit for analysis, which is electrically isolated from the sensing and transmission unit. The data received as a function of time $Q(t)$ were analyzed to obtain various parameter values that provide information on the insulation status of the IGBT module, such as the amount of initial charge, absorption current, and conduction current under various conditions. On the basis of the ratio $Q(t) / Q_{0}$, where $Q_{0}$ is the amount of initial charge, the amount of charge accumulated in the IGBT modules under high-stress conditions was obtained. The compact system for accumulated charge detection will be convenient for evaluating the insulation characteristics of IGBT modules, which operate under harsh conditions in real power electronic devices such as those used in electric vehicles.

\section{Introduction}

Power electronic transistors have been developed for use in a wide range of devices ${ }^{(1)}$ such as the thyristors used in high-voltage transmission grid systems, gate-commutated turn-off/gate turn-off (GCT/GTO) thyristors, high-voltage insulated gate bipolar transistor (IGBT) modules, ${ }^{(2)}$ high-voltage intelligent power modules (HV-IPM), high-speed railway operation control systems, electric vehicles, and industrial robots. These power electronic devices operate under high electric fields and high temperatures. Therefore, heat radiation from a power tip of such a device is an important issue. ${ }^{(3,4)}$

*Corresponding author: e-mail: takada@a03.itscom.net https://doi.org/10.18494/SAM.2019.2118 
Figure 1 shows a cross-sectional view of an IGBT module. The power tip radiates large amounts of heat generated during high-voltage and high-current operation, and the heat spreader uniformly spreads the heat in the layer. However, thermal energy is conducted through the insulation sheet to the base plate, which is in contact with a radiator. Since they are assembled in a multilayer structure, each IGBT element is electrically isolated by inserting an insulation sheet as shown in Fig. 1. To ensure the stable operation of these IGBT modules under harsh conditions, excellent insulation sheets with high thermal conduction have been developed by various methods, such as the impregnation of an insulation sheet with nanoparticles. ${ }^{(5,6)}$

However, a nonuniform electric field develops in the insulation sheet because of electric charge accumulation under high-dc and high-temperature conditions, causing the deterioration and electric breakdown of the insulation sheet. It is very important to determine the electric charge accumulation characteristics in the insulation layer of power devices for the safe operation of IGBT modules. Previously, the characteristics of insulation materials were conventionally evaluated by measuring the electric leakage current of insulation materials using a picoammeter. However, it was difficult to evaluate the electric charge accumulation from such measurements. Thus, the evaluation method was replaced; instead of depending on leakage current measured using a picoammeter, the characteristics of charge accumulation were evaluated by the pulsed electroacoustic (PEA) method. ${ }^{(7,8)}$ However, it was also difficult to use the PEA method for devices with complicated shapes, such as electric power cables and power devices such as IGBT modules. More recently, we have developed the $Q(t)$ method for the evaluation of the characteristics of charge accumulation in insulation materials with complex shapes.

For the measurement of electric charges accumulated in electric devices, a new measurement system using the $Q(t)$ method has been proposed for products with complicated shapes. For example, the $Q(t)$ method was applied to the evaluation of gamma-ray-irradiated coaxial cables by measuring the amount of residual electron-hole pair charge. ${ }^{(9)}$ The method was also applied to the evaluation of insulation of water-tree deteriorated power coaxial cables. ${ }^{(10)}$ In this study, the $Q(t)$ method was applied to the evaluation of electric charge accumulation in the insulation layer of power devices, particularly in IGBT modules. Although the shape of IGBT modules is complex, we can obtain the amount of electric charge accumulated in the insulation layer under

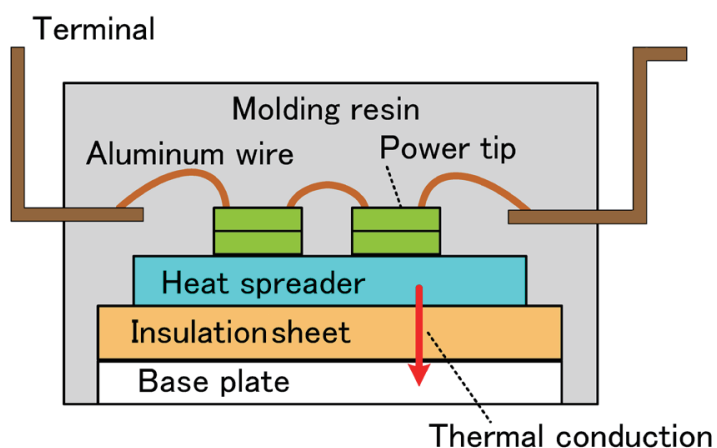

Fig. 1. (Color online) Cross-sectional view of IGBT module. 
various conditions, for example, at various applied voltages (100 to $5000 \mathrm{~V})$ and temperatures ( 25 to $180{ }^{\circ} \mathrm{C}$ ) using the charge accumulation evaluation system we developed. In this report, we describe the fabrication and practical application of the compact system for the evaluation of charge accumulation whose measurement principle is based on the $Q(t)$ method.

\section{Principles of Measurement of Insulation Characteristics}

Presently, the characteristics of insulation materials were conventionally evaluated by electric conduction measurement using a picoammeter. However, it was not easy to accurately evaluate the characteristics of insulation materials using the data obtained using a picoammeter. Figures 2 and 3 respectively show the measurement circuits and the results of their measurement by the conventional and new $Q(t)$ methods for comparison.

\subsection{Conventional picoammeter method}

In the evaluation of the electric conduction of a dielectric material, a picoammeter is usually used to measure the leakage current of the insulation material under a dc electric field. As
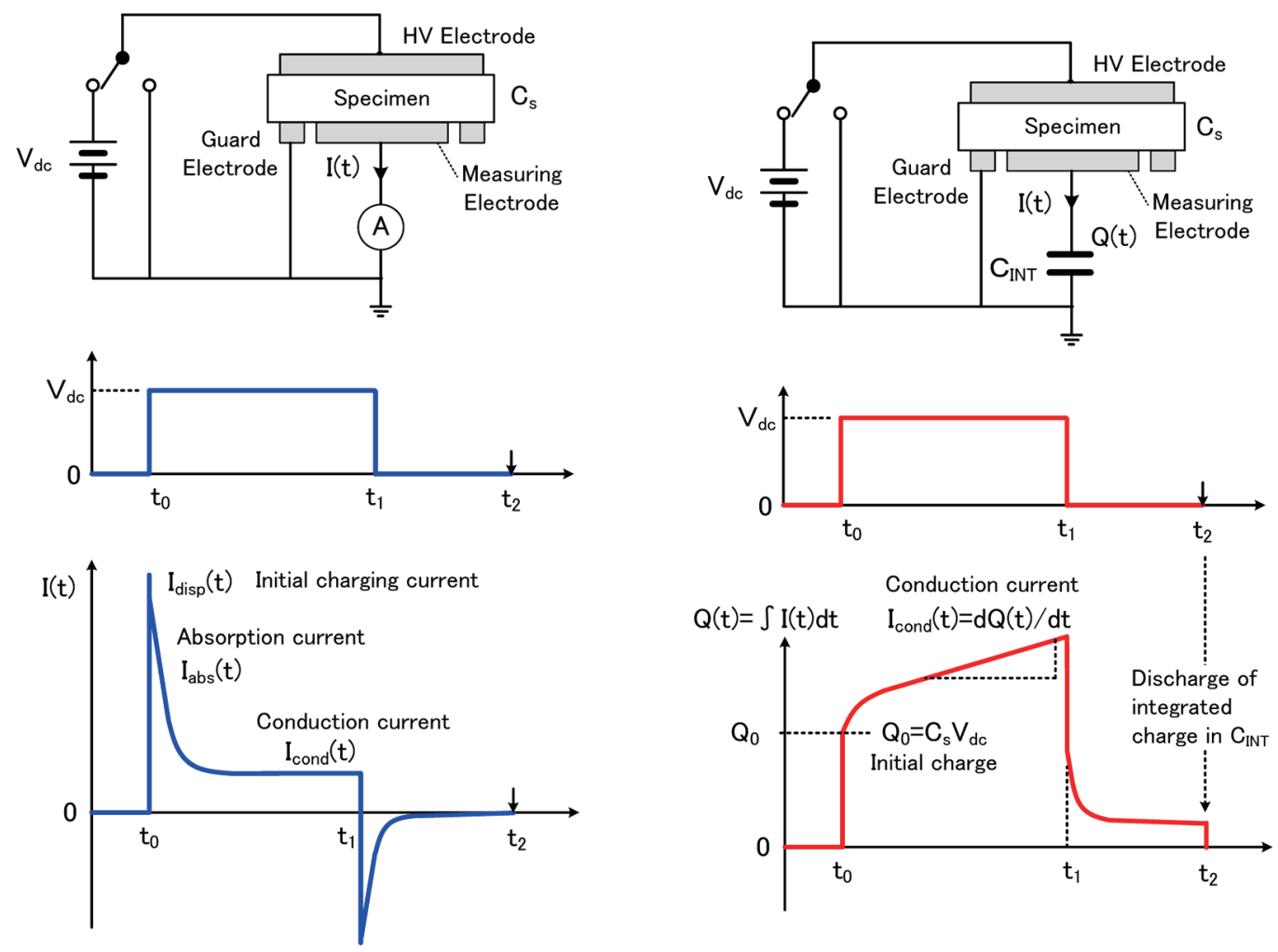

Fig. 2. (Color online) Conventional method (picoammeter) for evaluating electric insulation property.

Fig. 3. (Color online) $Q(t)$ method for evaluating electrical insulation property. 
shown in Fig. 2, an instantaneous charging current $\left[I_{\text {disp }}(t)\right]$ appears immediately after the application of a dc voltage $\left(V_{d c}\right)$, then an absorption current $\left[I_{a b s}(t)\right]$ flows into the sample after the initial displacement current, and finally a conduction current $\left[I_{\text {cond }}(t)\right]$ flows upon reaching equilibrium. ${ }^{(11)}$ The electric conductivity $\kappa$ of the test sample can be obtained by measuring the conduction current $I_{c o n d}(t)$ and applied voltage $V_{d c}$ as follows.

$$
\begin{gathered}
\frac{I_{\text {cond }}}{S}=\kappa \frac{V_{d c}}{d}, \\
\kappa=e n \mu,
\end{gathered}
$$

where $S$ is the surface area of the measuring electrode and $d$ is the thickness of the sample. The electric conductivity $\kappa$ is defined by Eq. (2), where en is the electric carrier density $\left(\mathrm{C}^{\mathrm{m}} \mathrm{m}^{3}\right)$ and $\mu$ is the mobility of electric carriers $\left(\mathrm{m}^{2} / \mathrm{Vs}\right)$. It is assumed that $e n$ and $\mu$ are constants inside the test sample.

Here, the electric conductivity $\kappa$ of the test samples of the polymeric insulation material is calculated. For a $100-\mu \mathrm{m}$-thick test sample, the surface area of the measuring electrode (S) is $5 \mathrm{~cm}^{2}$, the applied voltage $V_{d c}$ is $1000 \mathrm{~V}$, and the conduction current is $10 \mathrm{pA}$. Then, the conductivity $\kappa$ is $2 \times 10^{-15} \mathrm{~S} / \mathrm{m}$. In this measurement, the duration of voltage application to the test sample is usually about $5 \mathrm{~min}(300 \mathrm{~s})$. We now consider the physical meaning of the obtained conductivity of $2 \times 10^{-15} \mathrm{~S} / \mathrm{m}$. Here, the dielectric relaxation time $(\tau)$ is given as

$$
\tau=\frac{\varepsilon_{0} \varepsilon_{r}}{\kappa}
$$

where $\varepsilon_{0}$ is a dielectric constant in free space, which is $8.854 \times 10^{-12} \mathrm{~F} / \mathrm{m}$, and $\varepsilon_{r}$ is the relative permittivity of the test sample. By using $\varepsilon_{r}=2.2$ and $\kappa=2 \times 10^{-15} \mathrm{~S} / \mathrm{m}$ for Eq. (3), we calculate the dielectric relaxation time $\tau$ to be $5000 \mathrm{~s}$. The measurement time of $300 \mathrm{~s}$ is much shorter than the dielectric relaxation time of $5000 \mathrm{~s}$. It means that the conduction current $I_{\text {cond }}(t)$ does not reach the equilibrium state at $300 \mathrm{~s}$. That is, the front of electric charge carriers that started from one electrode does not reach the opposite electrode because en and $E$ are nonuniform in the test sample. Therefore, it is not accurate to use Eq. (1) for calculating the electric conductivity obtained using $\kappa=2 \times 10^{-15} \mathrm{~S} / \mathrm{m}$, which was obtained relatively soon after the application of the test voltage. From the above argument, the charge movement in polymeric insulation materials is important in the evaluation of the characteristics of such materials. That is, it is important to determine whether electric charge accumulation occurs in the insulation material under a dc electric stress in the evaluation of the characteristics of insulation materials.

Recently, the characteristics of electric insulation materials for use under high-dc-electric fields have been intensively studied because of the prevalent use of these insulation materials in dc power systems, for example, in dc-dc inverter systems of electric vehicles. To determine their characteristics, it is necessary to accurately evaluate the electric charge accumulation 
status in insulation materials under de voltage application at operating temperatures. A new measurement system based on the $Q(t)$ method is proposed to study the electric charge accumulation characteristics. The measurement principle of the $Q(t)$ method is introduced next.

\subsection{Current integration $Q(t)$ method}

Figure 3 shows the basic measurement concept of the $Q(t)$ method. In the new method, the picoammeter shown in Fig. 2 is replaced with a capacitor $\mathrm{C}_{\mathrm{INT}}$ for integrating electric current in the circuit, as shown in Fig. 3. As a result, the electric current can be integrated as $Q(t)$, which is given by Eq. (4), where $Q_{0}\left(=C_{s} V_{d c}\right)$ is the initial charge given by the product of the capacitance of the test sample $\left(C_{s}\right)$ and the applied voltage $\left(V_{d c}\right), I_{a b s}(t)$ is the absorption current, and $I_{\text {cond }}(t)$ is the conduction current, as shown in Figs. 2 and 3.

$$
Q(t)=Q_{0}+\int_{0}^{t} I_{a b s}(t) d t+\int_{0}^{t} I_{\text {cond }}(t) d t
$$

The first term $Q_{0}\left(=C_{s} V_{d c}\right)$ is the amount of charge at the electrode surfaces induced by the applied dc voltage. The second term represents the amount of electric charge that is obtained by integrating the absorption current $I_{a b s}(t)$ with respect to time, which indicates that electric charge carriers move in the sample and form space charges until the electric current reaches the equilibrium state. The third term represents the amount of electric charge that is obtained by integrating the conduction current $I_{\text {cond }}(t)$ with time after reaching the equilibrium state. In this case, the amount of electric charge supplied from the voltage power source is equal to that of conductive charge passing through the sample.

\section{$2.3 Q(t)$ measurement system}

Figure 4 shows the conceptual diagram of the measurement system for evaluating the characteristics of electric charge accumulation in the insulation layer of the IGBT module that was constructed on the basis of the concept of the $Q(t)$ method (AD-9832A; A\&D Company Limited). To all the connected terminals of the IGBT module, de voltages from 100 to $5000 \mathrm{~V}$ are applied. The IGBT module is placed on a plate heater for temperature control. The base plate (see Fig. 1) of the IGBT module and the plate heater are connected to the ground. Therefore, in the $Q(t)$ unit we developed, the integration capacitor $\mathrm{C}_{\mathrm{INT}}$ is placed on the highvoltage side of the power source, as shown in Fig. 4.

\subsection{Fabrication of measurement system}

The $Q(t)$ measurement system is composed of two units as shown in Fig. 5. The first unit includes the capacitor $\mathrm{C}_{\mathrm{INT}}$ for current integration, an analog-digital converter (ADC), and a transmission unit (ZigBee transmitter) with an antenna. Figure 6 shows the inside view of the electronic circuit of the $Q(t)$ measurement system whose diagram is shown in Fig. 5. The 


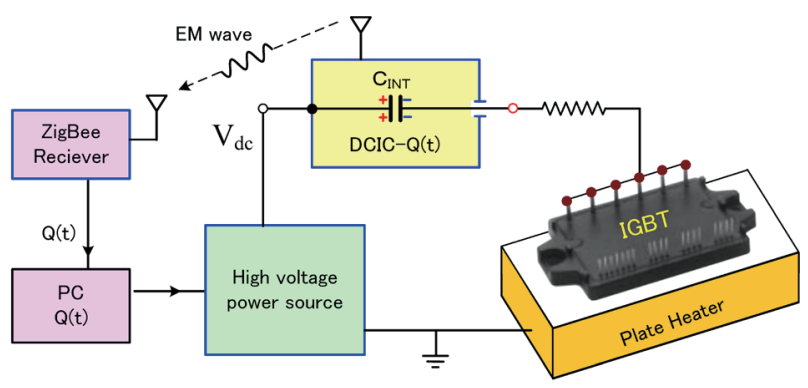

Fig. 4. (Color online) Current integration charge measurement system. The test sample is IGBT-M.

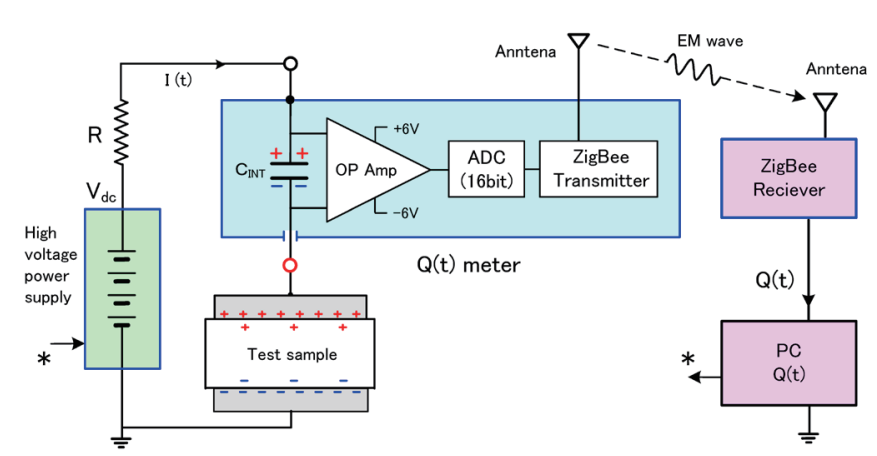

Fig. 5. (Color online) $Q(t)$ measurement system.

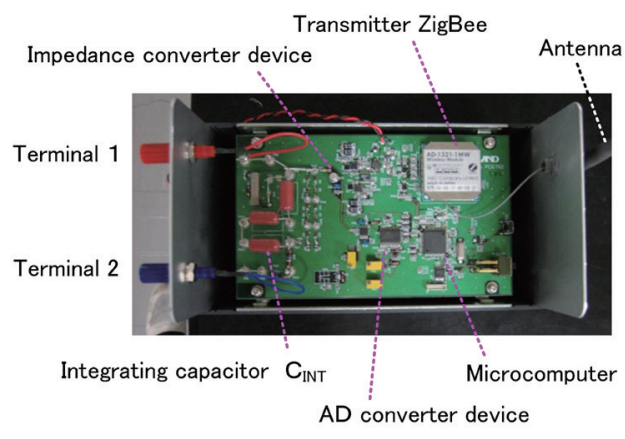

Fig. 6. (Color online) Inside view of $Q(t)$ meter electronic circuit. Dimensions: [150 (w) $\times 220(\mathrm{l})$ $\left.\times 100(\mathrm{~d}) \mathrm{mm}^{3}\right]$.

second unit is a personal computer connected to a wireless receiver, which receives data from the transmission unit. Since all the power required for the transmitter unit is supplied by a battery (6 V, $300 \mathrm{mAh})$, the $Q(t)$ unit can be used as a floating device. It can also be used for on-site measurements.

To detect a wide range of small integrating currents $\left(10^{-13}-10^{-8} \mathrm{~A}\right)$ and guarantee stable measurements for a long time ( $1 \mathrm{~h}$ or longer), we chose a capacitor without leakage current $\left(\mathrm{C}_{\mathrm{INT}}\right)$ made of polypropylene film (leakage relaxation time constant $>10^{4} \mathrm{~h}$ ) and an operational (OP) amplifier (Texas Instruments LMC6482/NOPB) with the high-impedance input $\left(>10^{13} \Omega\right.$ ).

In addition, we chose a 16-bit $\mathrm{ADC}$ for the precise evaluation of the $Q(t)$ data for IGBT devices in a wide range of applied voltages of $40 \mathrm{~V}-10 \mathrm{kV}$, as shown in Fig. 7. Equation (5) shows the relationships among the integration capacitance $C_{I N T}$, the capacitance $C_{S}$ of the test sample, the dc application voltage $V_{d c}$, and the measuring voltage $V_{I N T}$ at the capacitance $C_{I N T}$. As the condition for measurements, $V_{d c}(40 \mathrm{~V}-10 \mathrm{kV}) \gg V_{I N T}(20 \mathrm{mV}-5 \mathrm{~V})$ is required as shown in Fig. 7. We then approximate Eq. (5) using $\beta C_{s}$, where the coefficient $\beta$ is the ratio of $V_{d c}$ to $V_{I N T .}$ In this study, $\beta$ was 2000.

$$
C_{I N T}=\frac{V_{d c}-V_{I N T}}{V_{I N T}} \times C_{s} \cong \frac{V_{d c}}{V_{I N T}} \times C_{s}=\beta \times C_{s}
$$




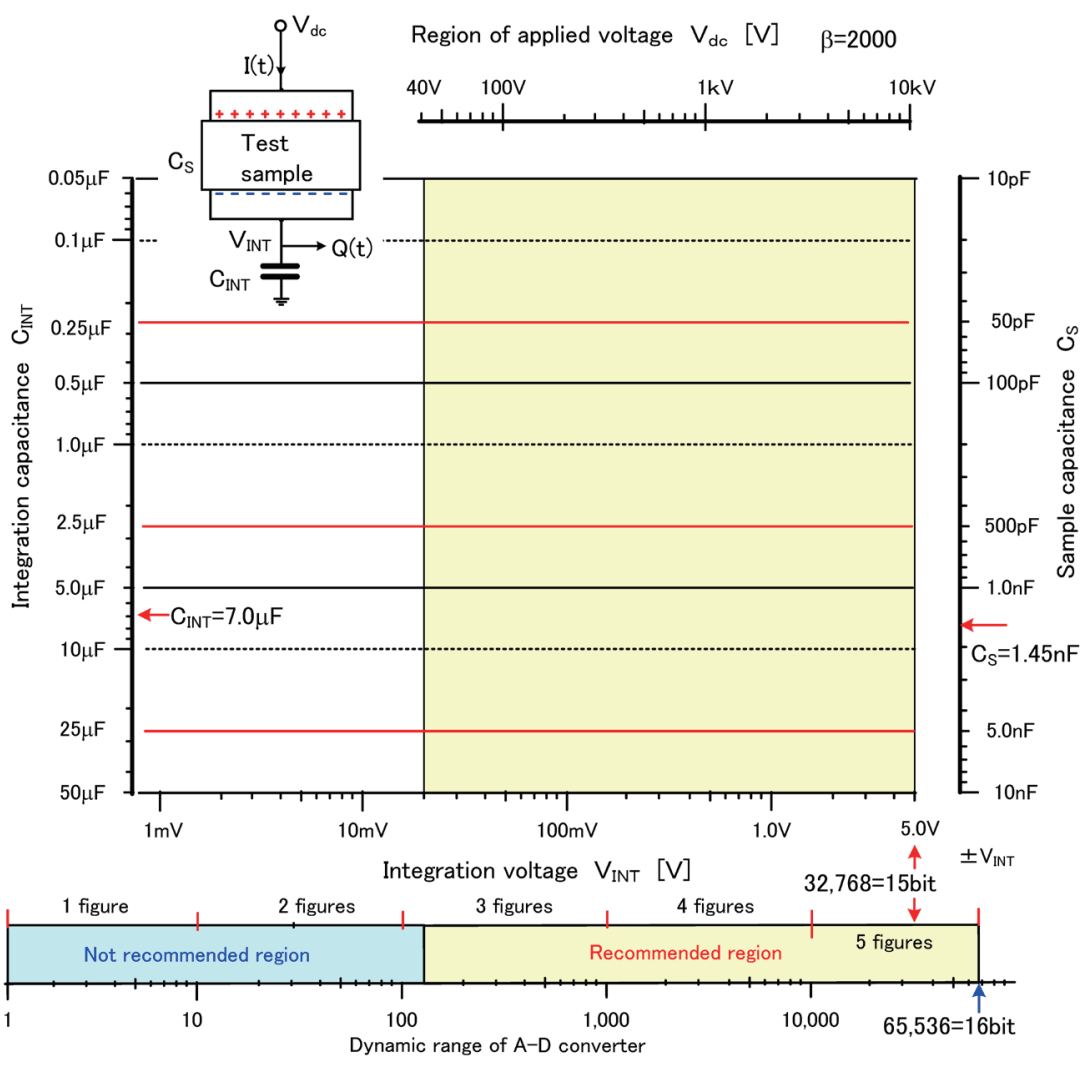

Fig. 7. (Color online) Relationships among $V_{d c}, V_{I N T}, C_{S}, C_{I N T}$, and dynamic range of ADC.

As the maximum range of measuring voltages is $V_{I N T}= \pm 5 \mathrm{~V}$, the maximum value of AD conversion at $V_{I N T}= \pm 5 \mathrm{~V}$ is 15 bits or 32768 . Then, the $V_{I N T}$ range of $\pm 20 \mathrm{mV}- \pm 5 \mathrm{~V}$ is guaranteed to be 3-5 digits, which guarantees highly accurate measurements. In the case of GBT-M1 [Fuji Electric (serial number MBR50UA120)], $\mathrm{Cs}=1.45 \mathrm{nF}$ (see Fig. 7 as example), we obtained the value of the integration capacitance $C_{I N T}=7.0 \mu \mathrm{F}$ from the relation of Eq. (5) and Fig. 7.

Here, we tested the stability of the $Q(t)$ system for long-term measurement, the results of which are shown in Fig. 8. We chose a small capacitance value $\left(C_{I N T}=0.1 \mu \mathrm{F}\right)$. We then tested $C_{I N T}$ under voltages $V_{I N T}=+2.5,0$, and $-2.5 \mathrm{~V}$, and measured $Q(t)$ for $12 \mathrm{~h}$. The charge leakage ratios $Q(t=12 \mathrm{~h}) / Q_{0}$ for $V_{I N T}=+2.5$ and $-2.5 \mathrm{~V}$ were 0.994 and 0.995 , respectively. We confirmed that the $Q(t)$ system is very stable because practically no charge leakage was observed.

\section{Interpretation of $Q(t)$ Data}

\subsection{Verification of $Q(t)$ measurement results}

Basic measurements were carried out to confirm the measurement results. The electric charge induced $\left(Q_{0}=C_{S} V_{d c}\right)$ on the electrode surface was measured immediately after applying 

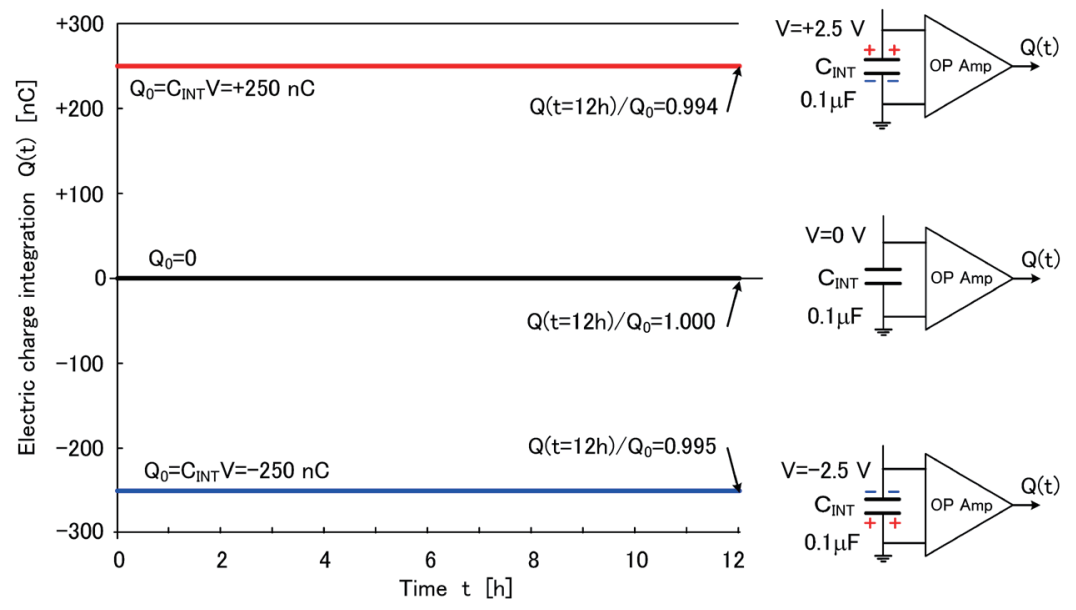

Fig. 8. (Color online) Stability test result of full $Q(t)$ measurement system over long time.

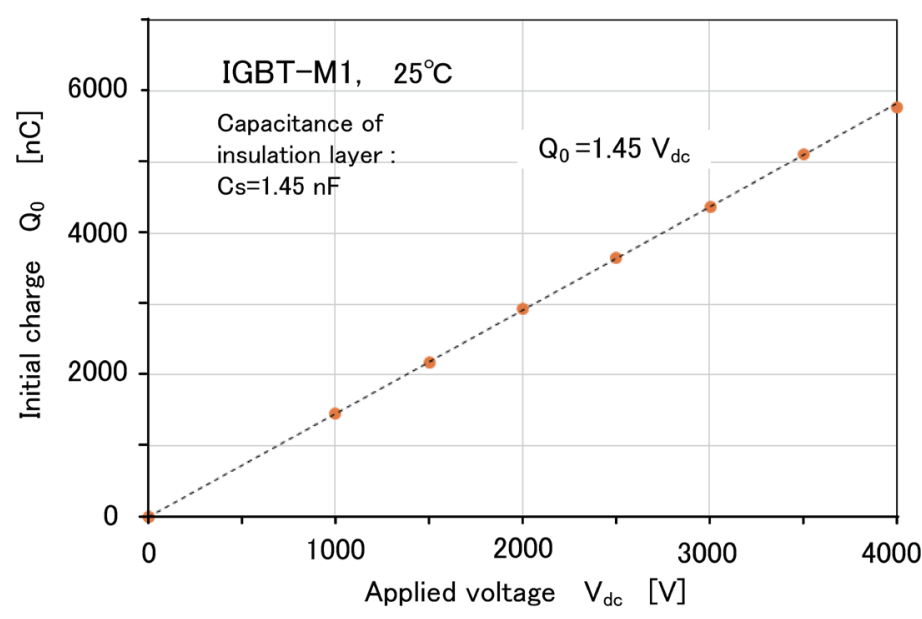

Fig. 9. (Color online) Relationship between $Q_{0}$ and $V_{d c}$ of IGBT-M1.

a high voltage to the test sample. The result of the measurement at that time point indicates the amount of electric charge induced on the electrodes, which is proportional to the applied voltage $V_{d c}$. Figure 9 shows the linear relationship between $Q_{0}$ and $V_{d c}$ at $25{ }^{\circ} \mathrm{C}$. In addition, we can obtain the capacitance of the insulation layer of IGBT-M1 from the slope of the relationship between $Q_{0}$ and $V_{d c}$ in Fig. 9, which is $C_{S}=1.45 \mathrm{nF}$.

\section{2 $Q(t)$ data for IGBT module}

Figure 10 shows $Q(t)$, which indicates the amount of charge accumulated in the insulation layer of IGBT-M1 under voltages from (a) 100 to $500 \mathrm{~V}$ and (b) 1000 to $5000 \mathrm{~V}$ applied for $180 \mathrm{~s}$ at $40^{\circ} \mathrm{C} . C_{I N T}=7.0 \mu \mathrm{F}$ was chosen from the conditions $V_{d c}=100$ to $5000 \mathrm{~V}$ and $C_{S}=1.45$ $\mathrm{nF}$ shown in Fig. 7. Figure 11 shows $Q(t)$, which indicates the amount of charge accumulated 

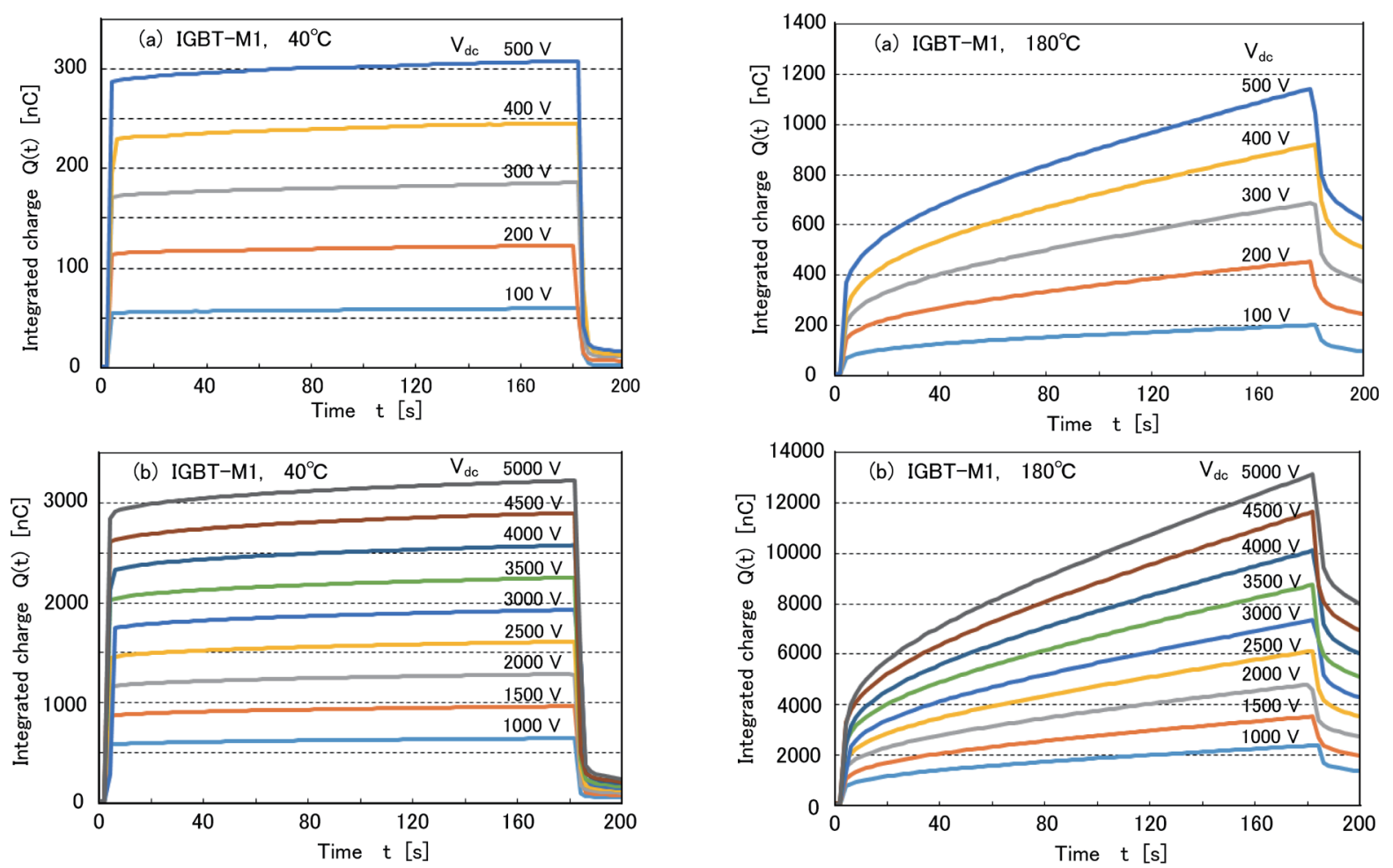

Fig. 10. (Color online) $Q(t)$ characteristic $\left(V_{d c}\right.$, $100-5000 \mathrm{~V})$ of IGBT-M1 sample at $40{ }^{\circ} \mathrm{C}$.

Fig. 11. (Color online) $Q(t)$ characteristic $\left(V_{d c}\right.$, $100-5000 \mathrm{~V})$ of IGBT-M1 sample at $180^{\circ} \mathrm{C}$.

in the insulation layer of IGBT-M1, under applied voltages (a) from 100 to $500 \mathrm{~V}$ and (b) 1000 to $5000 \mathrm{~V}$ for $180 \mathrm{~s}$ at $180{ }^{\circ} \mathrm{C}$. At a low temperature of $40{ }^{\circ} \mathrm{C}$ in Fig. 10 , the $Q(t)$ values were slightly higher than the $Q_{0}$ values in the wide range of applied voltages (100 to $\left.5000 \mathrm{~V}\right)$. On the other hand, at a higher temperature of $180^{\circ} \mathrm{C}$ in Fig. 11, the $Q(t)$ values were significantly larger than the $Q_{0}$ values in this wide range of applied voltages. These results indicate that the electric charge accumulation characteristics strongly depend on the applied voltage and temperature of the module.

\section{3 $Q(t) / Q_{0}$ electric charge ratio}

To further study the charge accumulation characteristics, we selected IGBT-M1 as a test sample. The $Q(t)$ at the applied voltage of $500 \mathrm{~V}$ at $160{ }^{\circ} \mathrm{C}$ was analyzed (Fig. 12). The initial amount of induced electric charge $\left(Q_{0}\right)$ obtained was $335 \mathrm{nC}$. However, $Q(t=180 \mathrm{~s})$ increased to $678 \mathrm{nC}$ at $160{ }^{\circ} \mathrm{C}$ after the application of $500 \mathrm{~V}$. Therefore, the electric charge ratio $Q(t=180 \mathrm{~s}) / Q_{0}$ increased to 2.02 . To discuss the characteristics of electric charge accumulation in the sample, $Q(t=180 \mathrm{~s}) / Q_{0}$ was calculated and the results are shown in Fig. 13. The electric charge ratio $Q(t) / Q_{0}$, is given by Eq. (6). The effect of temperature on the charge accumulation ratio is also shown in Fig. 13. The right-hand side of Eq. (6) has three terms. 


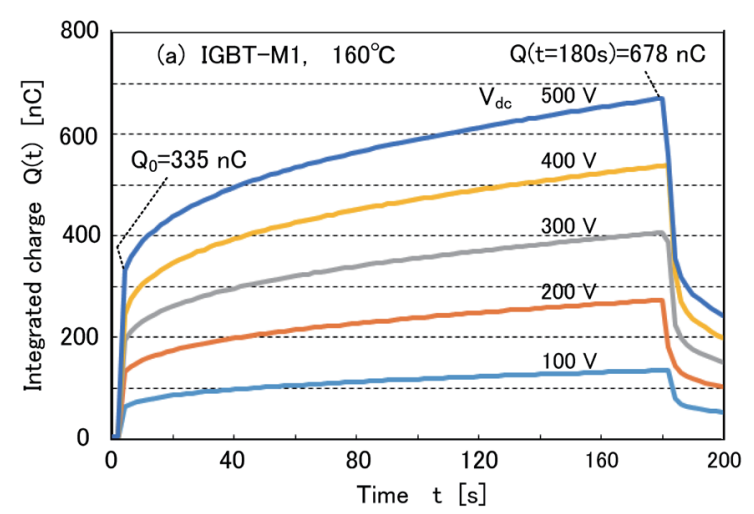

Fig. 12. (Color online) Dependence of $Q(t)$ characteristics on applied voltage for IGBT-M1 at $160{ }^{\circ} \mathrm{C}$.

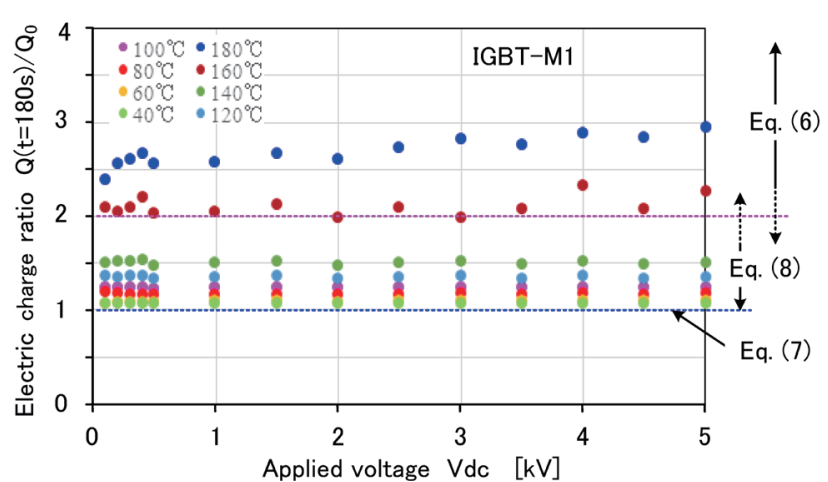

Fig. 13. (Color online) Relationship between integrated charge ratio $\left(Q(t=180 \mathrm{~s}) / Q_{0}\right)$ and applied voltage $V_{d c}$ for IGBT-M1.

$$
\begin{gathered}
\frac{Q(t)}{Q_{0}}=1+\frac{\int_{0}^{t} I_{a b s}(t) d t}{Q_{0}}+\frac{\int_{0}^{t} I_{\text {cond }}(t) d t}{Q_{0}} \\
\frac{Q(t)}{Q_{0}}=t \\
\frac{Q(t)}{Q_{0}}=1+\frac{\int_{0}^{t} I_{a b s}(t) d t}{Q_{0}}
\end{gathered}
$$

\subsubsection{Immediately after voltage application}

When $Q(t) / Q_{0}=1$, which is the case for Eq. (7), the second and third terms on the righthand side of Eq. (6) are zero because there is neither absorption current $\left[I_{a b s}(t)\right]$ nor conduction current $\left[I_{\text {cond }}(t)\right]$. All the electric charge is stored on the surface of the electrode, indicating no electric charge accumulated in the insulation layer. In this case, the internal electric field is uniform throughout the insulation layer. The electric charge ratio $Q(t=180 \mathrm{~s}) / Q_{0}$ is almost 1.05 in Fig. 13 at voltages from 100 to $5000 \mathrm{~V}$ at $40{ }^{\circ} \mathrm{C}$. Therefore, at near room temperature, no electric charge accumulation occurred in the IGBT-M1 tested in the wide range of applied voltages.

\subsubsection{Appearance of absorption current}

At temperatures from 60 to $140{ }^{\circ} \mathrm{C}$, the absorption current $\left[I_{a b s}(t)\right]$ appears owing to electric charge movement from the electrodes into the insulation layer until the movement reaches 
equilibrium. In this case, the third term on the right-hand side of Eq. (6) $I_{\text {cond }}(t)$ can be zero; therefore, Eq. (8) holds before the equilibrium state is reached. The electric charge ratio in this state is within $1<Q(t=180 \mathrm{~s}) / Q_{0}<1.5$ at voltages from 100 to $5000 \mathrm{~V}$ (Fig. 13). As electric charge accumulation proceeds in the insulation layer, the electric field distribution in this layer is non-uniform. This condition is caused by space charge accumulation.

\subsubsection{Period of conduction current}

During this period, the absorption current $I_{a b s}(t)$ is almost zero, and the conduction current $I_{\text {cond }}(t)$ is dominant. In Fig. 13, the electric charge ratio $Q(t=180 \mathrm{~s}) / Q_{0}$ during this period is greater than 2.0 under applied voltages from 100 to $5000 \mathrm{~V}$ and high temperatures from 160 to $180{ }^{\circ} \mathrm{C}$. When the conduction charge carriers move in the insulation layer, the electric field distribution in the insulator becomes almost uniform again. During this period, we can apply the ohmic law in Eq. (1) to describe the characteristics of the insulation layer. Regarding the results shown in Fig. 13, the electric charge ratio $Q(t=180 \mathrm{~s}) / Q_{0}$ was analyzed only for 180 s. If we increase the measurement time to, for example, $3600 \mathrm{~s}$, we may obtain a different $Q(t=3600 \mathrm{~s}) / Q_{0}$ ratio for the IGBT-M1 sample tested.

\subsection{Temperature dependence of $Q(t) / Q_{0}$}

Figure 14 shows $Q(t=180 \mathrm{~s}) / Q_{0}$ measured in a wide range of temperatures from 40 to $180{ }^{\circ} \mathrm{C}$. The $Q(t)$ at a low temperature of $40{ }^{\circ} \mathrm{C}$ is shown in Fig. 10, where the electric charge ratio $Q\left(t=180 \mathrm{~s}\right.$ ) $/ Q_{0}$ was almost 1.05 (see Fig. 13) even when the applied voltage $V_{d c}$ was increased to $5000 \mathrm{~V}$. From this result, we can conclude that only a small amount of space charge accumulated near the electrodes at this temperature. On the other hand, at a higher temperature of $180{ }^{\circ} \mathrm{C}$ (Fig. 11), the electric charge ratios obtained from the results in Fig. 11 are from 2.4 to 3.0 when the applied voltage $V_{d c}$ was $5000 \mathrm{~V}$ (Fig. 14). We assume that space charge accumulation occurs in the insulation layer and conduction current is formed during this period.

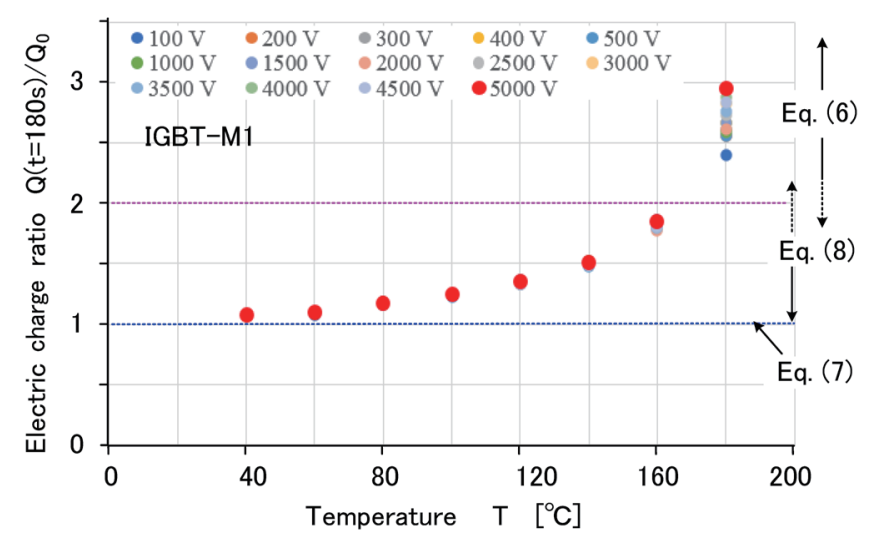

Fig. 14. (Color online) Relationship between integrated charge ratio $\left(Q(t=180 \mathrm{~s}) / Q_{0}\right)$ and temperature for IGBT-M1. 
The electric charge ratio $Q(t=180 \mathrm{~s}) / Q_{0}$ in Fig. 13 shows that the charge accumulation is more strongly dependent on the temperature of the sample than on the applied voltage. Figure 14, which is redrawn from the results of Fig. 13, shows the dependence of electric charge accumulation in terms of the ratio $Q(t=180 \mathrm{~s}) / Q_{0}$ on temperature. The accumulated charge ratio at $40{ }^{\circ} \mathrm{C}$ is close to 1 at $180 \mathrm{~s}$ from the initiation of voltage application. However, at temperatures of 80 and $140{ }^{\circ} \mathrm{C}$, the ratios were 1.2 and 1.5 , respectively. Finally, the ratios $Q(t=180 \mathrm{~s}) / Q_{0}$ at this same time at higher temperatures of 160 and $180^{\circ} \mathrm{C}$ were 1.9 and over 2.5 , respectively.

\subsection{Comparison between different IGBT-Ms}

We used two types of test sample, IGBT-M1 and GBT-M2 Mitsubishi [(Mitsubishi Intelligent Power Module (serial number, PM30RSF060)], which had different insulation characteristics because they were produced by different manufacturers. We presented the results of analysis of the electric charge accumulation characteristics in the insulation layer of IGBT-M1 in the above section. We now compare the charge accumulation characteristics of the insulation between IGBT-M1 and GBT-M2. The dependence of the electric charge accumulation ratios of IGBT-M1 and GBT-M2 on temperature is shown in Figs. 14 and 15, respectively. In the case of GBT-M2, $Q(t=180 \mathrm{~s}) / Q_{0}$ started to increase when the module temperature reached higher than $40^{\circ} \mathrm{C}$, and the ratio reached 1.5 when the temperature further increased to $60{ }^{\circ} \mathrm{C}$. However, in the case of GBT-M1, the ratio started to increase gradually but did not reach 1.5 until the temperature increased to $140{ }^{\circ} \mathrm{C}$. These results indicate that the electric charge accumulation characteristics of IGBT-M1 are better than those of IGBT-M2.

Finally, we discuss the physical meaning of charge accumulation characteristics in IGBT modules. Generally, electric charge accumulates between two conducting materials with an insulating material in the middle, which can be represented as a simple capacitor. For the purpose of this study, the IGBT modules used in this study can be represented by such a

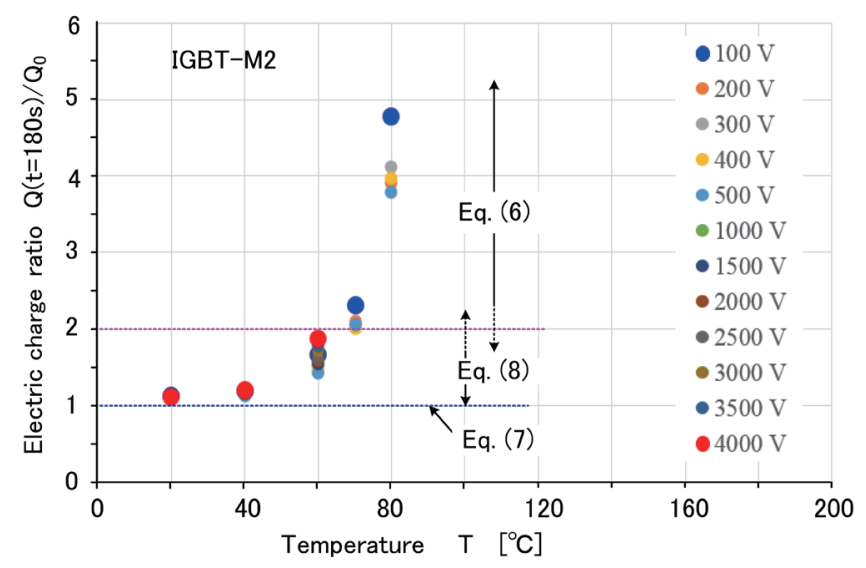

Fig. 15. (Color online) Relationship between integrated charge ratio $\left(Q(t=180 \mathrm{~s}) / Q_{0}\right)$ and temperature for IGBT-M2. 
capacitor. Figure 1 simply represents the concept of an IGBT module and does not necessary indicate the possible locations of charge accumulation. Charge accumulation in IGBT modules should strongly depend on the insulating materials used for the insulation structure and molding. Recently, ceramic materials such as $\mathrm{Si}_{3} \mathrm{~N}_{4}$ and AlN have been widely used as insulators for power modules, which have a high thermal conductivity and excellent insulating properties. ${ }^{(12-15)}$ Silicone gel and epoxy resin are also used as packing materials. Thus, there must be marked differences in insulating properties among IGBT modules. Our experimental results only indicate the amount of charge accumulated in a bulk module, which can be used to detect the IGBT modules that are prone to electrical breakdown. Our experimental results do not provide information regarding the exact locations of charge accumulation in modules and this can be the limitation of the use of the device developed in this study. It would be ideal if we can provide the internal structures and find the exact locations of charge accumulation; however, it is beyond the scope of this study.

\section{Conclusions}

The electric charge accumulation characteristics of the insulation layer of IGBT modules under electric and temperature stresses were studied using a new two-unit charge detection system we developed. The measurement principle of the system is based on the $Q(t)$ method we developed. Two types of power module, IGBT-M1 and IGBT-M2, were used as test samples, which had different insulation layer characteristics. The modules were subjected to various electric and thermal stresses, namely, dc voltages from 100 to $5000 \mathrm{~V}$ and temperatures from 40 to $180^{\circ} \mathrm{C}$. The electric charge ratio $Q(t=180 \mathrm{~s}) / Q_{0}$ for IGBT-M1 after the start of the application of an electric voltage of $1000 \mathrm{~V}$ at $80{ }^{\circ} \mathrm{C}$ is 1.2 . On the other hand, the $Q(t=180 \mathrm{~s}) / Q_{0}$ for IGBT-M2 under the same conditions is 4.1. These results indicate that IGBT-M1 has better insulation characteristics than IGBT-M2. For our future work, we plan to fabricate a compact one-chip charge-accumulation-sensing unit that can be used for on-site evaluation of insulation characteristics of IGBT modules and other power semiconductor devices.

\section{Acknowledgments}

The authors are grateful to Ms. Maimi Mima and Mr. Daiki Hanazawa for obtaining experimental data.

\section{References}

1 www.mitsubishielectric.co.jp/semiconductors/products

2 N. Tokura: IEEJ Trans. IA-131-1 (2011) 1.

3 Y. Sakamoto: DENSO Tech. Rev. 16 (2011) 46.

4 M. Horio: Conf. Proc. PCIM (2011) 229.

5 K. Mimura, M. Masaki, Y. Nakamura, and T. Nishimura: IEICE Trans. C J94-C (2012) 434.

6 K. Mimura, Y. Nakamura, and M. Masaki: J. Photopolymer Sci. Technol. 28 (2015) 169.

7 Li Ying and T. Takada: IEEE Electr. Insul. Mag. 10 (1994) 16.

8 T. Takada: IEEE Trans. DEI 6 (1999) 519. 
9 T. Takada, Y. Fujitomi, T. Mori, T. Iwata, T. Ono, H. Miyake, and Y. Tanaka: IEEE Trans. DEI 24 (2017) 2549.

10 W. Wang, K. Sonoda, S. Yoshida, T. Takada, Y. Tanaka, and T. Kurihara: IEEE Trans. DEI 25 (2018) 94.

11 A. P. S. Tiwana and C. C. Reddy: IEEE Trans. DEI 25 (2018) 127.

12 M. Ishiko: R\&D Review of Toyota CRDL 39-4 (2004) 1 (in Japanese).

13 A. Wintrich, U. Nicolai, W. Tursky, and T. Reimann: Application Manual Power Semiconductors. SEMIKRON International GmbH, Nuremberg, Germany (2011).

14 K. Nakahara, N. Sakai, K. Nishikawa, Y. Yamaguchi, and K. Uchida: Mitsubishi Denki Giho 92 (2018) 167 (in Japanese).

15 N. Kanai, M. Hoya, and T. Tsuji: Fuji Electric J. 91 (2018) 215 (in Japanese). 